\title{
Kajian fungsi sosial-budaya ruang terbuka hijau publik Kecamatan Serpong, Kota Tangerang Selatan
}

\author{
Dinda Hindira Hastita ${ }^{1}$, Silia Yuslim² ${ }^{\star}$, Marselinus Nirwan Luru ${ }^{1}$ \\ 1. Prodi Perencanaan Wilayah dan Kota, Universitas Trisakti, Jl. Kyai Tapa No.1 Grogol, Jakarta, Indonesia \\ 2. Prodi Arsitektur Lanskap, Universitas Trisakti, Jl. Kyai Tapa No.1 Grogol, Jakarta, Indonesia \\ *E-mail: siliayuslim@trisakti.ac.id
}

\begin{abstract}
Study of the socio-cultural function of public green open space in Serpong District, South Tangerang City. Urban communities have a variety of activities and routines with high mobility. It takes a balance between busy activities and leisure activities where people have the freedom to communicate and interact in space. The area of public green open space in Serpong District has reached $28 \%$ of the total required by Law no. 26 article 29. Most of the green open space is located in certain housing areas, so that its utilization is more focused on residential residents. . Based on these facts, this study aims to discuss the extent to which the socio-cultural functions that must be carried out by public green open space outside of residential areas can meet the needs of people who live outside the existing residential areas. A study on the social functions of public green open space will be carried out in Serpong District, South Tangerang City, with samples of City Forest 2, Health Park, and Peace Park. This study used survey method using data collection instruments in the form of observations and questionnaires which were scored based on a Likert scale. Data analysis technique is using proportion (percentage) or frequency. From the research results, it is known that the social function of public green open space in City Forest 2, Health Park, and Peace Park has been achieved, namely as a communication medium for city residents, describing local cultural expressions, recreation areas, and educational and research facilities.
\end{abstract}

Keywords: public green open space, social-culture functions

\section{Pendahuluan}

Berdasarkan Peraturan Menteri Pekerjaan Umum No. 5 Tahun 2008 tentang Pedoman Penyediaan dan Pemanfaatan Ruang Terbuka Hijau di Kawasan Perkotaan, Ruang Terbuka Hijau (RTH) adalah area memanjang/jalur dan atau mengelompok, yang penggunaannya lebih bersifat terbuka, tempat tumbuh tanaman, baik yang tumbuh tanaman secara alamiah maupun yang sengaja ditanam. RTH dapat dibedakan menjadi RTH publik dan RTH privat. Keberadaannya diharapkan dapat memiliki fungsi ekologis, fungsi sosial dan budaya, fungsi ekonomi, serta fungsi estetika.

Sebagai RTH publik, suatu RTH dapat berperan sebagai sarana utama dalam menjalankan komunikasi antar penghuni untuk menciptakan suatu kehidupan bersama yang disepakati, Joga dan Ismaun (2011). Suatu RTH publik juga, sebaiknya dapat memenuhi kebutuhan masyarakat, seperti relaksasi, dan sebagai wadah bagi masyarakat untuk melakukan kegiatan aktif atau pasif di luar kegiatan sehari-hari masyarakat, Carr (1992). Untuk itu, RTH publik diharapkan dapat digunakan masyarakat untuk melakukan aktivitas, seperti berinteraksi dengan masyarakat lain, melakukan kegiatan seperti bermain, olahraga, belajar, atau hanya sekadar berjalan (Dollah, 2017; Hariz, 2013; Novitasari, 2019). Selain itu, juga diharapkan dapat digunakan sebagai wadah untuk melakukan aktivitas bersama, komunikasi sosial, tempat peralihan dan menunggu, sebagai sarana dan rekreasi, penghubung antara satu tempat dengan tempat lainnya, pembatas massa bangunan, sarana penelitian dan pendidikan, sarana untuk menciptakan kebersihan, kesehatan, dan keserasian, Persada (2019). Hal tersebut sejalan dengan fungsi sosial yang disebutkan pada Peraturan Menteri Pekerjaan Umum No. 5/PRT/M/2008, yaitu sebagai ruang interaksi sosial, sarana rekreasi, dan sebagai landmark kota, serta sebagai wadah interaksi, RTH publik, masyarakat juga dapat memanfaatkannya sebagai wadah rekreasi, olahraga, diskusi dan kegiatan lainnya. 
Pentingnya peran RTH publik dalam mewadahi fungsi sosial masyarakat, terutama sebagai wadah untuk berinteraksi bagi masyarakat, sangat berguna untuk melepas ketegangan atau stress yang dialami masyarakat perkotaan dan meningkatkan produktivitasnya, Dwiyanto (2009). Fungsi sosial RTH publik tidak dapat berdiri sendiri. Fungsi ini biasanya dikaitkan dengan keberadaan budaya setempat. Terkait dengan hal tersebut, maka suatu RTH publik juga harus dapat menggambarkan ekspresi budaya lokal, sebagai media komunikasi warga kota, tempat rekreasi dan sebagai wadah dan objek pendidikan dan penelitian, Firmansyah, et al. ( 2018).

Kota Tangerang Selatan, sebagai daerah pemekaran dari Tangerang, mengalami pertumbuhan yang sangat pesat. Pertumbuhan Kota Tangerang Selatan memperlihatkan bahwa sebagian besar wilayahnya diperuntukkan untuk pembangunan kawasan permukiman. Hal ini menurut Ikatan Ahli Perencana Indonesia (2017), sejalan dengan fungsinya sebagai salah satu kota satelit Jakarta dan salah satu dari sepuluh besar Kota Layak Huni Indonesia. Pertumbuhan dan perkembangan Kota Tangerang Selatan, telah mengacu pada Peraturan Daerah Kota Tangerang Selatan No. 9 Tahun 2019, penyediaan luas RTH minimal 30\% dari luas wilayah kota, dengan perincian 20\% RTH publik dan 10\% RTH privat. Berdasarkan Nasyith (2020), luas RTH yang tersedia telah mencapai $28 \%$, yaitu $39,968 \mathrm{Km} 2$ atau sebesar $3996,85 \mathrm{Ha}$ dari luas wilayah Kota Tangerang Selatan yang sebesar 147,19 Km2 atau sebear $14719 \mathrm{Ha}$. Sementara itu, berdasarkan Peta RTRW Kota Tangerang Selatan tahun 2018, pada kecamatan Serpong luas RTH yang tersedia adalah 9,81 Km2 atau $981 \mathrm{Ha}$ dari luas wilayahnya yang sebesar $24,04 \mathrm{Km} 2$ atau $2404 \mathrm{Ha}$. Jadi pencapaiannya telah 24,55\%. Dari aspek luasan, Kota Tangerang Selatan telah hampir memenuhi luasan yang ditargetkan. Tetapi perlu dicermati bahwa ketercapaian luasan RTH, terutama RTH publik ini terjadi karena adanya kewajiban pengembang dari kawasan perumahan untuk menyediakannya, sehingga keberadaan RTH publik lebih diperuntukan bagi kawasan perumahan tertentu. Sementara itu, masyarakat yang berada di luar kawasan permukiman tersebut juga membutuhkan keberadaan RTH publik sebagai wadah untuk berinteraksi sosial. Berangkat dari pertimbangan ini, maka peneltian ini dilakukan untuk melihat sejauh mana fungsi sosial-budaya yang harus diperankan RTH publik yang berada di luar kawasan perumahan, telah dapat memenuhi kebutuhan masyarakat yang berada di luar lingkungan perumahan.

Agar kajian fungsi sosial-budaya dapat dilakukan secara optimal, maka ditentukan 3 (tiga) lokasi studi dengan jenis RTH publik yang berbeda, berdasarkan pertimbangan bahwa keberadaan ketiga taman ini dapat dikatakan berada pada satu titik lokasi yang mudah dicapai atau berada di suatu kawasan yang masyarakat sekitarnya relatif membutuhkan keberadaannya. Lokasi pertama adalah Hutan Kota 2, merupakan RTH publik tipe Taman Kota yang melayani penduduk satu kota atau sebagian wilayah kota, sehingga dapat melayani penduduk Kecamatan Serpong dan kecamatan sekitarnya. Lokasi kedua, Taman Kesehatan, merupakan Taman Kelurahan, yang secara aksesibilitas, dapat memfasilitasi aktivitas masyarakat di luar skala kelurahan. Lokasi ketiga, Taman Perdamaian, merupakan Taman Warga, yang berada dalam kawasan padat penduduk.

\section{Metode}

Metode yang digunakan dalam penelitian ini adalah metode survey yang menggunakan instrument pengumpulan data berupa observasi dan kuesioner. Observasi dilakukan untuk melihat seberapa banyak masyarakat yang memanfaatkan fasilitas yang terkait dengan fungsi sosial-budaya yang ada di RTH publik. Penyebaran kuesioner dilakukan untuk melihat sejauh mana pengguna taman merasa dapat memanfaatkan taman yang ada bagi pemenuhan kebutuhannya terkait fungsi sosial-budaya. Kuesioner dilengkap dengan skor yan ditentukan berdasarkan skala likert dengan rentang skala penilaian yaitu: Sangat Tidak Setuju (= 1), Tidak Setuju (= 2), Ragu-ragu (= 3), Setuju (= 4), dan Sangat Setuju (= 5) Janti ( 2014). Berdasarkan nilai yang diperoleh, dihitunglah indeks dari tiap jawaban kuesioner. Untuk mendapatkan indeks $(\%)=$ (total skor $/$ skor maksimum) $\times 100 \%$. Variabel dan indikator penelitian ini terdapat pada Tabel 1. Tidak adanya data pengunjung tiap taman di pemerintahan menyebabkan populasi tidak dapat ditentukan. Oleh sebab itu, penentuan jumlah sampel dilakukan dengan menggunakan perhitungan dengan rumus: Lemeshow (1990). 


$$
\mathrm{n}=\frac{\mathrm{Z}^{2} \alpha / 2 * \mathrm{p}(1-\mathrm{p})}{\mathrm{d}^{2}}
$$

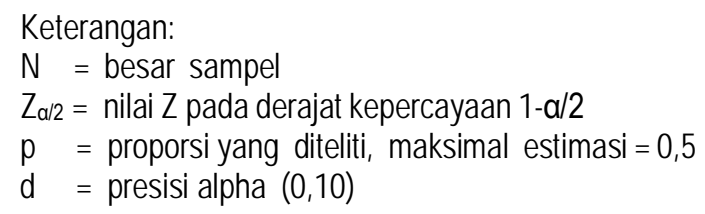

Jumlah populasi diasumsikan sebanyak 50\% $(p=0,5)$ masyarakat adalah pengunjung taman. Untuk presisi mutlak untuk menggunakan $10 \%(d=0,10)$ dengan derajat kepercayaan $95 \%$ dan nilai $Z$ pada derajat kepercayaan 1-a/2 dengan $a=0,05$ adalah 1,96. Berdasarkan perhitungan diperoleh 96 responden yang digunakan dalam penelitian ini. Responden ditentukan dengan kriteria berusia $\geq 17$ tahun, dan pada kuesioner dicantumkan jenis kelamin, alamat tinggal, dan pekerjaan. Hasil penyebaran kuesioner dianalisis menggunakan analisis distribusi proporsi (persentase). Untuk menentukan tingkat capaian indikator, dikelompokkan dalam; 1) katagori tinggi ( $\geq 66,7 \%)$, apabila jawaban responden menjawab sangat setuju dan setuju; 2) katagori sedang $(33,3 \% \leq$ indeks $\leq 66,7 \%)$, apabila jawaban responden menjawab ragu-ragu; 3 ) katagori rendah (<33,3\%), apabila responden menjawab tidak setuju dan sangat tidak setuju Tatang( 2010).

Tabel 1. Variabel Operasional dan Indikator Penelitian

\begin{tabular}{|c|c|c|c|}
\hline No & Variabel & Indikator & Sumber \\
\hline 1 & $\begin{array}{l}\text { Mencerminkan ekspresi budaya } \\
\text { lokal }\end{array}$ & $\begin{array}{l}\text { Taman memiliki ciri khas atau sebagai } \\
\text { landmark sebuah kota }\end{array}$ & $\begin{array}{l}\text { Persada, } 2019 \\
\text { Firmansyah, } 2018\end{array}$ \\
\hline 2 & Wadah komunikasi warga kota & $\begin{array}{l}\text { Pengunjung melakukan interaksi } \\
\text { dengan cara berbincang atau berdiskusi }\end{array}$ & $\begin{array}{l}\text { Persada, } 2019 \\
\text { Firmansyah, } 2018 \\
\text { Jatmiko, } 2016\end{array}$ \\
\hline 3 & Wadah rekreasi & Anak-anak dapat bermain & $\begin{array}{l}\text { Persada, } 2019 \\
\text { Firmansyah, } 2018\end{array}$ \\
\hline & & Pengunjung dapat melakukan piknik & $\begin{array}{l}\text { Persada, } 2019 \\
\text { Firmansyah, } 2018\end{array}$ \\
\hline & & Pengunjung dapat duduk-duduk santai & $\begin{array}{l}\text { Persada, } 2019 \\
\text { Firmansyah, } 2018\end{array}$ \\
\hline 4 & Wadah olah raga & Pengunjung dapat berolah raga & $\begin{array}{l}\text { Persada, } 2019 \\
\text { Dollah, } 2017 \\
\text { Jatmiko, } 2016\end{array}$ \\
\hline 5 & Pendidikan dan Penelitian & $\begin{array}{l}\text { Pengunjung dapat menambah wawasan } \\
\text { pengetahuan } \\
\text { Pengunjung dapat melakukan penelitian }\end{array}$ & $\begin{array}{l}\text { Persada, } 2019 \\
\text { Firmansyah, } 2018 \\
\text { Persada, } 2019 \\
\text { Firmansyah, } 2018\end{array}$ \\
\hline
\end{tabular}

\section{Hasil dan Pembahasan}

Kecamatan Serpong merupakan salah satu kecamatan dari Kabupaten Tangerang dengan luas wilayah $2.404 \mathrm{Ha}$ atau 16,33\% dari luas Kota Tangerang Selatan. Kecamatan Serpong memiliki 9 kelurahan, yaitu Kelurahan Buaran, Kelurahan Ciater, Kelurahan Cilenggang, Kelurahan Lengkong Gudang, Kelurahan Lengkong Gudang Timur, Kelurahan Lengkong Wetan, Kelurahan Rawa Buntu, Kelurahan Rawa Mekar Jaya, dan Kelurahan Serpong. Lokasi penelitian disajikan pada Gambar 1. 

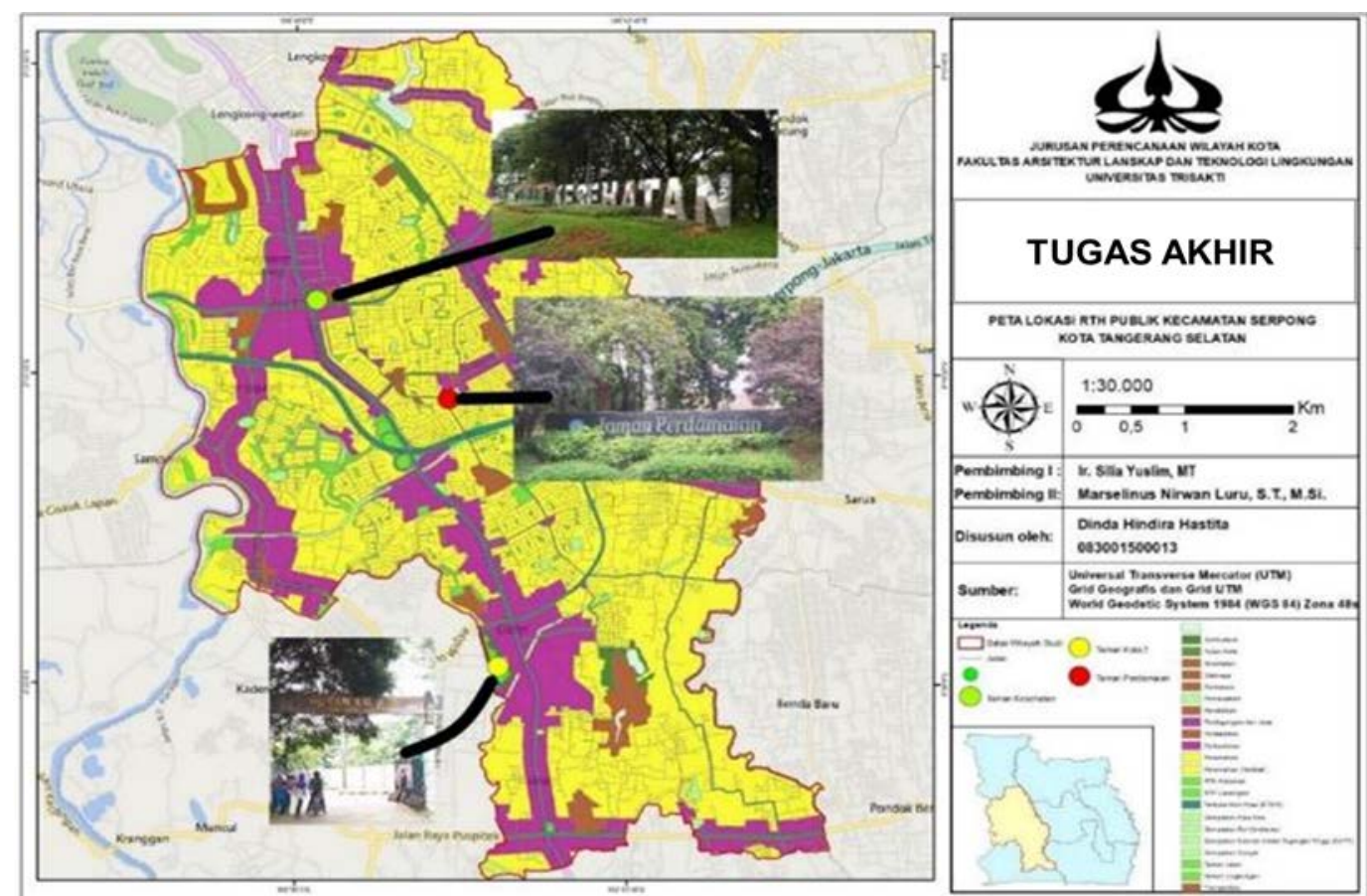

Gambar 1 Peta Lokasi Studi Penelitian

\subsection{Hutan Kota 2}

Hutan kota 2 merupakan taman aktif yang terdapat di Kecamatan Serpong, berada di jalan arteri sekunder Kota Tangerang Selatan (Jalan Tekno Widya), memiliki luas area 7,5 Ha. Hutan Kota 2 memiliki bentuk dan struktur hutan kota dengan tanaman yang berstrata, dimiliki dan dikelola oleh pemerintah Kota Tangerang Selatan. Berbagai macam fasilitas yang terdapat di sana, seperti jogging track, trek jalan refleksi, lapangan terbuka, gelanggang seni budaya, area bermain anak, musholla, toilet, dan lain-lain. Taman yang dibuka dari pagi hari hingga sore hari, biasa digunakan untuk berolah raga, seperti lari pagi, bersepeda, dan senam; rekreasi, seperti piknik, wisata air (perahu kayuh, sepeda air), dan berkuda; digunakan juga sebagai tempat bermain anak-anak dan berkesenian; serta tempat bersantai di gazebo dan bangku taman. Lahan parkir mobil dan motor juga terdapat pada taman ini. Taman ini juga memiliki Jaletreng Riverpark yang digunakan sebagai wisata air menjadi landmark bagi kota Tangerang Selatan. Tetumbuhan yang terdapat di sana berupa pohon-pohon besar dilengkapi dengan papan informasi yang memberikan informasi tentang pohon tersebut yang dapat memberikan infomarsi yang mengedukasi masyarakat dan keberadaan hutan juga dapat menjadi wadah bagi peneliti untuk melakukan penelitian. Peta hasil observasi pada Gambar 2.

\subsection{Taman Kesehatan}

Taman Kesehatan terletak di sebelah jalan arteri Kota Tangerang Selatan, sehingga akses ke taman ini sangat mudah, baik bagi para pengendara kendaraan pribadi maupun kendaraan umum. Taman ini biasa dikunjungi masyarakat sekitar pada pagi dan sore hari untuk berolahraga, seperti jogging. Taman dilengkapi dengan beberapa fasilitas pendukung seperti: berbagai alat berolaraga, jogging track, jalur untuk sepeda atau otoped, trek relaksasi, bangku taman di setiap sudut taman dan sebelah kanan/kiri trek jogging. Taman juga memiliki plaza di tengah taman yang digunakan sebagai tempat untuk berkumpul pengunjung untuk melakukan suatu aktivitas. Sesuai dengan jenisnya, yaitu Taman Kelurahan, taman ini tidak dilengkapi dengan lahan parkir, sehingga pengunjung yang datang dengan kendaraan pribadi harus memarkirkan kendaraannya di luat taman. Foto hasil observasi pada Gambar 3. 


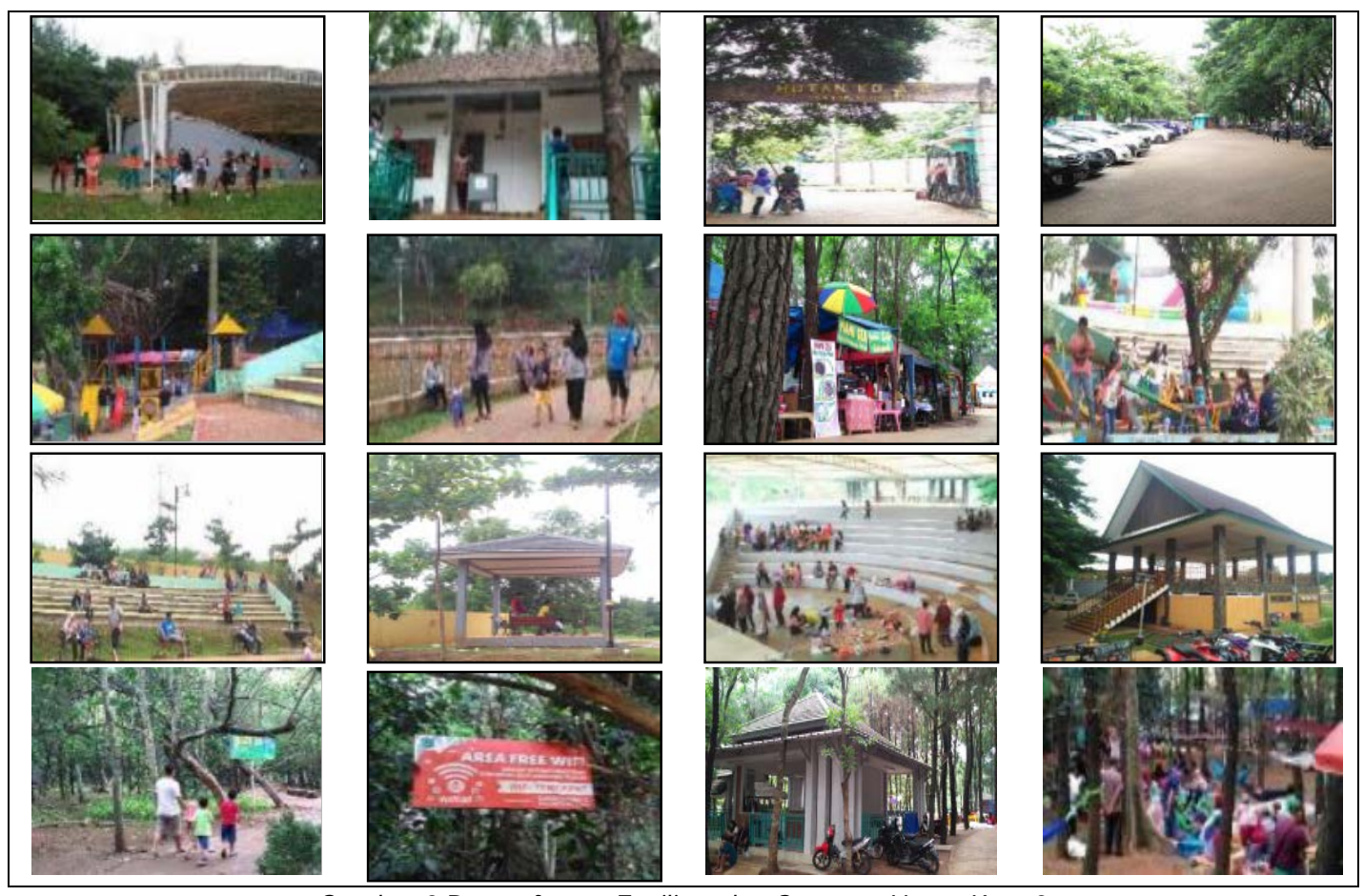

Gambar 2 Pemanfaatan Fasilitas dan Suasana Hutan Kota 2
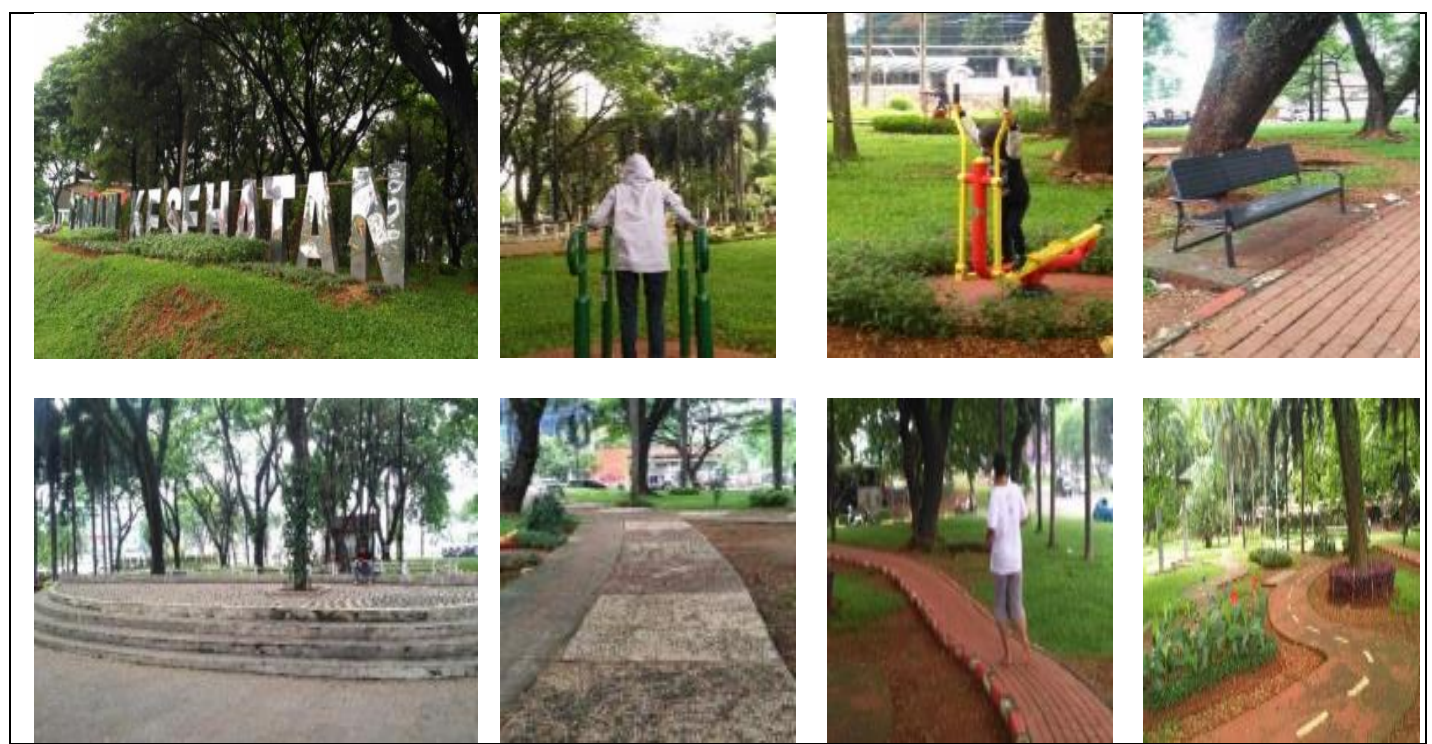

Gambar 3 Pemanfaatan Fasilitas dan Suasana Taman Kesehatan (Dinda, 2020)

\subsection{Taman Perdamaian}

Taman Perdamaian terletak dekat dengan perumahan dan sarana pendidikan, dilengkapi dengan playground untuk anak-anak bermain. sehingga sering digunakan untuk tempat untuk mengasuh anak-anak setiap pagi dan sore. Taman juga dilengkapi dengan bangku taman dan anak-anak tangga yang melingkari plaza yang biasa digunakan pengunjung untuk duduk-duduk santai dan berbincang bersama pengunjung lain. Letaknya di tengah permukiman padat, taman ini biasa dijadikan tempat berkumpul dan menjadi spot gathering oleh komunitas di sekitarnya, seperti komunitas BMX dan skateboard. Plaza di tengah taman sering digunakan anak-anak dan remaja untuk bermain skateboard. Sesuai dengan jenisnya, taman ini memang diperuntukkan bagi masyarakat yang tinggal di sekitar taman, sehingga tidak tersedia toilet Foto hasil observasi disajikan pada Gambar 4. 


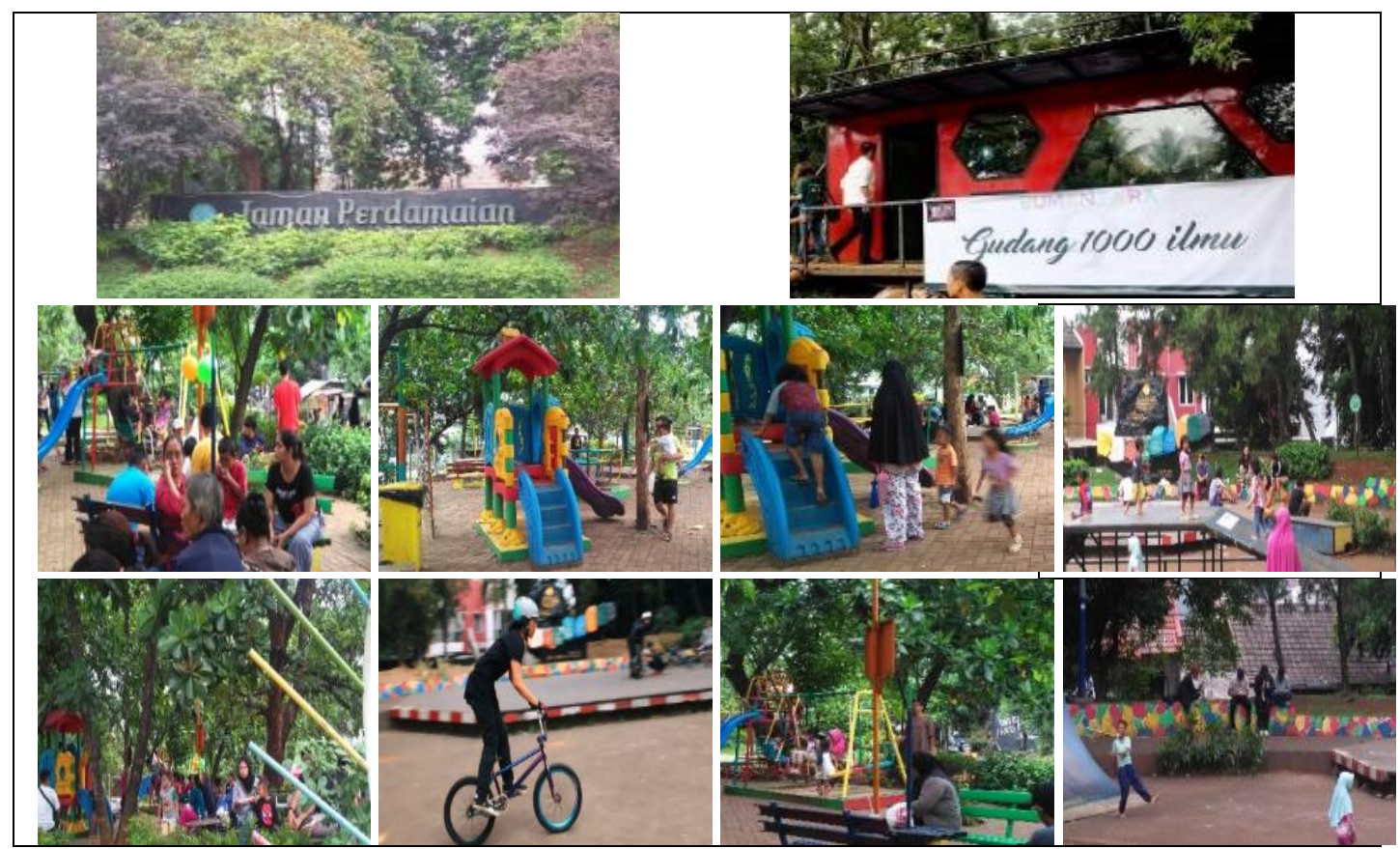

Gambar 4 Pemanfaatan Fasilitas dan Suasana Taman Perdamaian (Dinda, 2020)

Berdasarkan hasil observasi, seluruh indikator terpenuhi. Seluruh RTH publik yang dijadikan lokasi studi digunakan secara optimal sebagai wadah rekreasi, olah raga, komunikasi antar warga/masyarakat, taman juga dimanfaatkan sebagai sarana bagi peningkatan wawasan pengetahuan, serta setiap taman memiliki kekhasannya sendiri. Hasil observasi ini juga didukung oleh hasil penyebaran kuesioner kepada pengunjung ketiga RTH publik yang menjadi lokasi studi. Hasil rekapitulasi dari penyebaran kuesioner disajikan pada Tabel 2.

Tabel 2 Hasil Rekapitulasi Penyebaran Kuesioner

\begin{tabular}{|c|c|c|c|c|c|}
\hline \multirow[t]{2}{*}{ No } & \multirow[t]{2}{*}{ Variabel } & \multirow[t]{2}{*}{ Indikator } & \multicolumn{3}{|c|}{$\begin{array}{l}\text { Hasil Rekapitulasi dari Penyebaran } \\
\text { Kuesioner }\end{array}$} \\
\hline & & & $\begin{array}{c}\text { Hutan Kota } \\
2\end{array}$ & $\begin{array}{l}\text { Taman } \\
\text { Kesehatan }\end{array}$ & $\begin{array}{c}\text { Taman } \\
\text { Perdamaian }\end{array}$ \\
\hline 1 & $\begin{array}{l}\text { Mencerminkan eks- } \\
\text { presi budaya lokal }\end{array}$ & $\begin{array}{l}\text { Taman memiliki ciri khas atau } \\
\text { sebagai landmark sebuah kota }\end{array}$ & $67,8 \%$ & $60,8 \%$ & $68 \%$ \\
\hline 2 & $\begin{array}{l}\text { Wadah komunikasi } \\
\text { warga kota }\end{array}$ & $\begin{array}{l}\text { Pengunjung melakukan interaksi } \\
\text { dengan cara berbincang atau } \\
\text { berdiskusi }\end{array}$ & $87 \%$ & $76 \%$ & $76,5 \%$ \\
\hline \multirow[t]{3}{*}{3} & Wadah rekreasi & Anak-anak dapat bermain & $77,8 \%$ & $80 \%$ & $78 \%$ \\
\hline & & $\begin{array}{l}\text { Pengunjung dapat melakukan } \\
\text { piknik }\end{array}$ & $63,4 \%$ & $40,5 \%$ & $68,7 \%$ \\
\hline & & $\begin{array}{l}\text { Pengunjung dapat duduk-duduk } \\
\text { santai }\end{array}$ & $90,8 \%$ & $70,8 \%$ & $82,5 \%$ \\
\hline 4 & Wadah olah raga & Pengunjung dapat berolah raga & $90,8 \%$ & $80 \%$ & $70,5 \%$ \\
\hline \multirow[t]{2}{*}{5} & $\begin{array}{l}\text { Pendidikan dan } \\
\text { Penelitian }\end{array}$ & $\begin{array}{l}\text { Pengunjung dapat menambah } \\
\text { wawasan pengetahuan }\end{array}$ & $70,4 \%$ & $60,5 \%$ & $69,7 \%$ \\
\hline & & $\begin{array}{l}\text { Pengunjung dapat melakukan } \\
\text { penelitian }\end{array}$ & $66,5 \%$ & $45 \%$ & $65 \%$ \\
\hline
\end{tabular}

Berdasarkan hasil reapitulasi penyebaran kuesioner, terlihat bahwa hampir semua indikator dari variabel yang digunakan untuk melihat sejauh mana fungsi sosial-budaya RTH publik yang menjadi lokasi studi telah memenuhi kebutuhan masyarakat, teruitama kebutuhan sebagai wadah rekreasi, komunikasi, dan olah raga. Ini terlihat dari katagori persentase dari hasil rekapitulasi penyebaran kuesioner dari tiap indikator 
yang termasuk katagori sedang hingga tinggi, bahkan bebeapa diantaranya termasuk dalam katagori tinggi. Artinya, masyarakat Kota Tangerang Selatan, terutama kecamatan Serpong telah merasakan manfaat dari fungsi sosial-budaya yang diperankan ketiga RTH publik yang dijadikan lokasi studi.

\section{Simpulan}

Berdasarkan peneltian ini dapat disimpulkan bahwa fungsi sosial-budaya yang diperankan oleh ruang terbuka hijau publik, yaitu Hutan Kota 2, Taman Kesehatan, dan Taman Perdamaian, secara keseluruhan telah dapat memenuhi kebutuhan masyarakat dalam lingkup kecamatan maupun kota. Berbagai aktivitas yang terkait dengan interaksi sosial dapat dilakukan oleh masyarakat Kota Tangerang Selatan. Fungsi sosial yang diperankan oleh ruang terbuka hijau publik sudah berjalan dengan cukup baik. Namun demikian, penyempurnaan harus tetap dilakukan, karena beberapa indikator masih masuk dalam katagori sedang. Diharapkan hasil dari penelitian ini dapat menjadi acuan bagi pemerintah atau pengembang di Kota Tangerang Selatan untuk tetap menyempurnakan RTH publik yang ada dan mengembangkan RTH publik lainnya, sehingga pemenuhan kebutuhan masyarakat akan wadah interaksi, rekreasi dan olah raga yang mengekspresikan budaya lokal akan semakin tercapai. Salah satu bentuk upaya tersebut, dengan memberikan wadah bagi pagelaran seni budaya Tangerang Selatan berupa Tari Nong Anggrek atau Tari Putri Anggrek yang menjadi ikon Kota Tangerang Selatan.

\section{Daftar Pustaka}

Carr, Stephen. 1992. Public Space. Press Syndicate of University of Cambridge. Australia.

Dollah, Aris Sakkar. 2017. Analisis RTH dari Aspek Keterlaksanaan Fungsi Sosial di Kota Makassar. Jurnal IImu Arsitektur. Universitas Muhammadiya Makssar. ISSN 2614-3976.

Dwiyanto, Agung. 2009. Kuantitas Dan Kualitas Ruang Terbuka Hijau Di Permukiman Perkotaan. Jurnal Nasional Arsitektur: Universitas Diponegoro. 30 (2).

Firmansyah, A. R., Soeriaatmadja, I., \& Wulanningsih, R. (2017).. A Set of Sustaiinable Urban Landscape Indicators and Parameters to Evaluate Urban Green Open Space inn Bandung City. IOP Prosiding Conf. Series: Earth and Environmental Science 179012016.

Hariz, Aulia. 2013. Evaluasi Keberhasilan Taman Lingkungan di Perumahan Padat Sebagai Ruang Terbuka Publik Studi Kasus: Taman Lingkungan di Kelurahan Galur, Jakarta Pusat. Jurnal Perencanaan Wilayah dan Kota 24 (2).

Ikatan Ahli Perencana Indonesia . 2017. Indonesia Most Livable City Index 2017.

Janti, Suhar. 2014, Analisis Validitas dan Reliabilitas dengan Skala Likert terhadap Pengembangan Si/Ti dalam Penentuan Pengambilan Keputusan Penerapan Strategic Planning pada Industri Garmen, Yogyakarta: Prosiding Seminar Nasional Aplikasi Sains \& Teknologi (SNAST) 2014

Joga, Nirwono dan Iwan Ismaun. 2011. RTH 30\%! Resolusi (Kota) Hijau. PT. Gramedia Pustaka Utama. Jakarta.

Nasyith, Dzakiy, Ananto Aji, Juhadi. 2020. Analisis Ketersediaan Oksigen Untuk Kebutuhan Ruang Terbuka Hijau di Kota Tangerang Selatan Tahun 2017. Journal Geo Image 9 (1).

Novitasari, Dian Fajar, dan Ardy Maulidy N. 2017. Karakteristik Pengunjung dan Aktivitasnya Terhadap Penggunaan Taman Kota Sebagai Ruang Sosial di Taman Keplaksari Kabupaten Jombang. Jurnal Teknik ITS 6 (2).

Persada, Citra, dkk. 2019. Kajian Fungsi Sosial Budaya, Estetika, dan Ekologi Taman "Hutan Kota" Way Halim Kota Bandar Lampung. Prosiding SINTA 2018, 1. pp. 246-250. ISSN 2655-2914

Kementrian Pekerjaan Umum. 2008. Peraturan Menteri Pekerjaan Umum No. 5/PRT/M/2008 tentang Pedoman iPedoman iPenyediaan dan Pemanfaatan Ruang Terbuka Hijau idi Kawasan Perkotaan. Kementrian Pekerjaan Umum. Jakarta.

Pemerintah Kota Tangerang Selatan. 2019. Peraturan daerah Tangeraang Selatan No 9 Tahun 2019 tentang perubahan atas peraturan daerah no 15 tahun 2011 tentang reancana tata ruang wilayah kota tangerang selatan tahun 2011-2031. Pemerintah Kota Tangerang Selatan.

Tatang M. Amirin. 2010. Skala Likert : Penggunaannya dan Analisis Datanya. https://tatangmanguny.wordpress. com/2010/11 